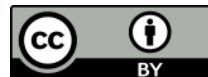

\title{
Política arquivística de preservação digital: um estudo sobre sua aplicabilidade em instituições públicas federais
}

William Silva

Mestre em Patrimônio Cultural, pela Universidade Federal de Santa Maria (UFSM). Docente do Instituto Federal de Educação, Ciência e Tecnologia do Rio Grande do Sul (IFRS)

Daniel Flores

Professor do Programa de Pós-Graduação
Profissional em Patrimônio Cultural da
Universidade Federal de Santa Maria
(PPGPPC/UFSM). Docente do Departamento de
Documentação/ Curso de Arquivologia da
Universidade Federal de Santa Maria

http://dx.doi.org/10.1590/1981-5344/3187

O presente artigo apresenta parte dos resultados obtidos em uma pesquisa de mestrado sobre a preservação do patrimônio documental arquivístico da Federação Espírita do Grande do Sul (FERGS), desenvolvida no Programa de Pós-Graduação Profissional em Patrimônio Cultural da Universidade Federal de Santa Maria (PPGPPC/UFSM). O objetivo geral da pesquisa é analisar a aplicação de estratégias de preservação para fins de elaboração de um Plano de Preservação do Patrimônio Documental Arquivístico da FERGS. Para subsidiar a referida pesquisa, optou-se pela realização de um levantamento de dados que identificasse políticas arquivísticas sobre preservação digital e como ela se efetivaria nas instituições, para que fosse possível analisar o universo da referida instituição, a FERGS. O resultado desse levantamento de dados, realizado em cinquenta e cinco instituições públicas brasileiras, mostrou que boa parte delas, ou seja, cerca de noventa e um por cento, não possui uma política arquivística de preservação digital e nenhuma delas possui um Plano de Preservação Digital que efetivasse essa política. Isso mostra que as políticas públicas sobre preservação digital emanadas pelo Arquivo Nacional não 
estão sendo efetivamente implantadas dentro das instituições públicas federais, corroborando para o desenvolvimento de ações para a melhoria desse cenário.

Palavras-chave: Preservação digital. Política arquivística de preservação digital. Plano de preservação digital.

\section{Archival policy of digital preservation: a study on its applicability in federal public institutions}

This article presents part of the results obtained in a master's research on the preservation of the archival documentary heritage of the Southern Spiritist Federation (FERGS), which has developed in the Professional Postgraduate Program in Cultural Patrimony of the Federal University of Santa Maria (PPGPPC/ UFSM). The general objective of the research is to analyze the application of preservation strategies for the elaboration of a Plan of Preservation of the FERGS Archival Documentary Heritage. In order to subsidize this research, it was decided to carry out a data survey that identified archival policies on digital preservation and how it would be effective in the institutions, so that it would be possible to analyze the universe of said institution, FERGS. The result of this data collection, carried out in fifty-five Brazilian public institutions, showed that a good part of them, or about ninety-one percent, does not have an archival preservation digital policy and none of them has a Digital Preservation Plan To implement this policy. This shows that the public policies on digital preservation emanated by the National Archives are not being effectively implemented within the federal public institutions, corroborating the development of actions to improve this scenario.

Keywords: Digital preservation. Archival policy of digital preservation. Plan of digital preservation.

Recebido em 11.06.2017 Aceito em 22.06.2018

\section{Introdução}


Segundo Flores e Baggio (2013) a preservação digital surgiu na segunda metade do século $X X$ e foi intensificada no início do século seguinte, a partir de uma necessidade de preservar materiais digitais que rapidamente se tornaram obsoletos e/ou degradados. "As preocupações acerca da preservação digital no mundo tiveram sua primeira expressividade no contexto mundial a partir de um trabalho realizado no International Concil on Archuves (ICA), em 1970" (FLORES; BAGGIO, 2013, p. 12).

Apenas as bibliotecas, os arquivos, os centros e institutos de pesquisa, bem como organismos governamentais criaram conteúdo digital relevante durante o final do século XX, conforme retrata Arellano (2004). Neste período do início do século XXI, quando o autor afirmava esses fatos, ele já alertava que muitas coleções digitais consideradas importantes para a sociedade estavam sendo construídas fora das bibliotecas por diferentes organizações, ou sendo publicadas diretamente na Internet.

Arellano (2006, p. 2) afirma que dependendo do contexto, o significado da terminologia Preservação Digital pode possuir vários entendimentos. Olhando a perspectiva a partir do universo dos profissionais da informação, o autor diz que a preservação digital é "a infraestrutura e o comprometimento institucional necessário para proteger a informação representada digitalmente".

Já Ferreira (2006) define-a como sendo uma atividade responsável por garantir que a comunicação (emissor e receptor) seja realizada através do tempo, além do espaço, mas para que ela se faça é necessário assegurar que todos os níveis (físico, lógico e conceitual) estejam acessíveis e interpretáveis.

Boeres e Cunha (2012) consideram a preservação digital como parte de um conjunto de serviços, políticas e especialistas que constituam o contexto do ciclo de vida da informação digital.

O referido trabalho tem como objetivo analisar a aplicação de estratégias de preservação digital para fins de elaboração de um Plano de Preservação do Patrimônio Documental Arquivístico da Federação Espírita do Rio Grande do Sul, como produto da pesquisa de mestrado sobre a preservação do patrimônio documental arquivístico da Federação Espírita do Rio Grande do Sul.

Para tanto, o trabalho foi divido em 6 (seis) seções: Seção 1 Introdução; Seção 2 - Políticas de preservação digital; Seção 3 - Plano de Preservação Digital; Seção 4 - Procedimentos metodológicos; Seção 5 Análise e discussão dos resultados; Seção 6 - Considerações finais.

\section{Políticas de preservação digital}

No Brasil, a preocupação na preservação digital, com uma abordagem voltada para o campo da arquivologia, foi fomentada pelo Conselho Nacional de Arquivos (Conarq) por ser atribuição precípua do referido órgão a definição de políticas de arquivos públicos e privados e 
orientação normativa que contribuam para a gestão e proteção especial aos documentos de arquivo, seja qual for o suporte.

A Câmara Técnica de Documentos Eletrônicos (CTDE), do Conselho Nacional de Arquivos (Conarq), realizou pesquisas mais profundas relacionadas à gestão e preservação de documentos digitais (FLORES; BAGGIO, 2013)

A Carta para a Preservação do Patrimônio Arquivístico Digital é uma das políticas nacionais elaboradas pela CTDE do Conarq para as instituições brasileiras. Segundo o Conarq (2005) os documentos arquivísticos precisam manter sua fidedignidade e autenticidade para serem capazes de fornecer evidência das suas ações, contribuindo para a ampliação da memória social, "vez que registram informações culturais, históricas, científicas, técnicas, econômicas e administrativas" (CONARQ, 2004, p. 2).

Não seria diferente, conforme observa o Conarq (2005), para os documentos arquivísticos digitais. A suscetibilidade à degradação física e à obsolescência tecnológica dos documentos arquivísticos digitais é o grande desafio atual, exigindo que as organizações planejem ações arquivísticas a serem observadas antes e ao longo de todo o ciclo de vida dos documentos, para que com o planejamento e concepção de sistemas eletrônicos seja possível garantir a ausência de perdas e adulteração de registros.

Segundo o Conarq (2005) é importante alertar os governos, organizações públicas e privadas, instituições de ensino e pesquisa e todos outros setores da sociedade brasileira, comprometidos com a inclusão informacional sobre outros problemas, tais como a dependência social da informação digital, a rápida obsolescência da tecnologia digital, a incapacidade dos atuais sistemas eletrônicos de informação em assegurar a preservação de longo prazo, a fragilidade intrínseca do armazenamento digital, a complexidade e custos da preservação digital, e a multiplicidade de atores envolvidos.

Considerando esses aspectos, o Conarq (2005) compreende que as instituições arquivísticas de caráter público e privado, seja no âmbito da indústria e tecnologia da informação e informação, seja nas instituições de ensino e pesquisa, necessitam implementar ações que envolvem a elaboração de estratégias e políticas, o estabelecimento de normas e a promoção desse conhecimento.

Já o InterPARES 2 Project (THE INTERNATIONAL RESEARCH ON PERMANENT AUTHENTIC RECORDS IN ELECTRONIC SYSTEMS, 2007), especialmente no documento "Diretrizes do preservador", traz uma relação de recomendações aos grupos responsáveis pela preservação a longo prazo de documentos arquivísticos digitais. O objetivo do documento é enfatizar algumas áreas que são especialmente relevantes à preservação de documentos arquivísticos digitais autênticos, e que demonstraram serem muitas vezes negligenciadas, por incluir, de forma apressada, documentos arquivísticos digitais em repositórios de arquivo.

A preocupação na construção de um planejamento para a criação dos documentos, no início do ciclo vital, deve contemplar ações que 
auxiliam na identificação das potencialidades tecnológicas, tal qual afirma Santos (2012), bem como os procedimentos quanto ao uso de sistemas informatizados que gerenciarão os documentos, e que são sustentados por aspectos legais e normativos da própria institucional.

Santos (2012) também relembra sobre a importância da presença de profissionais habilitados a realizarem levantamentos dos fluxos processuais, observando a produção documental e descartando, para fins de registro e elaboração do plano de classificação, as atividades que não geram documentos.

Innarelli $(2015$, p. 156) demonstra que a visão sobre a preservação digital e os desafios que ela implica são urgentes para as instituições, pois há uma necessidade premente "na elaboração de políticas que atendam as questões relacionadas à preservação dos documentos arquivísticos digitais, uma vez que estes documentos já são uma realidade, dir-se-ia até irreversível".

Para o autor, trata-se de documentos que devam ser preservados para que as instituições cumpram com seus papéis e para a humanidade não esqueça do seu próprio passado, e se houver políticas de gestão e de preservação de documentos arquivísticos as instituições poderão utilizar desse conhecimento acumulado e aprender com as experiências, que sejam elas positivas ou negativas (INNARELLI, 2015).

Uma política de preservação de documentos arquivísticos digitais, segundo Innarelli (2015), deve estar atenta aos aspectos relativos à autenticidade, acesso e a preservação em si dos documentos arquivísticos digitais.

A aplicação dos aspectos de autenticidade dos documentos arquivísticos, tal como é preconizada no âmbito analógico, também é compreendida no âmbito digital, ou seja, nos documentos arquivísticos digitais, mas a forma de garanti-la é diferente, ao passo que nos documentos em suporte analógico ${ }^{1}$ as adulterações e corrupções são perceptíveis, já nos documentos digitais não é perceptível (INNARELLI, 2015).

A carência de políticas voltadas à presunção de autenticidade de documentos arquivísticos digitais ameaça a garantia que os documentos institucionais sejam considerados autênticos, especialmente, quando submetidos à migração de sistemas, softwares, hardwares e/ou suportes (INNARELLI, 2015).

No cenário brasileiro, Innarelli (2015) retrata que algumas instituições responsáveis pela gestão e preservação de documentos arquivísticos digitais não priorizam o desenvolvimento de políticas de preservação digital, ao passo que muitas delas sequer possuem políticas de gestão de documentos arquivísticos. Essa postura, conforme elucida o autor, traz sérios prejuízos ao patrimônio arquivístico, pois todas as práticas arquivísticas são consequências das políticas de gestão e preservação, sendo praticamente impossível a sua realização.

\footnotetext{
Foi substituído o termo "documento convencional" por "suporte convencional", adequando a terminologia à perspectiva abordada pelo Projeto InterPARES, conforme especificado no tópico 3.2 dessa dissertação.
} 
Com base nesses referenciais teóricos acerca da preservação digital e a importância da implementação de políticas que contribuam para a sustentabilidade dessa ação nas instituições públicas brasileiras seguimos para a compreensão sobre o uso e a relevância de um Plano de Preservação Digital.

\section{Plano de preservação digital}

Barbedo, Corujo e Sant' Ana (2011) afirmam que as organizações necessitem de um documento estratégico que determine quais os procedimentos a serem realizados para evitar a obsolescência tecnológica e a perda de informação, o que promoverá a proatividade na definição e implementação de estratégias de preservação digital.

Para tanto, os autores propõem a construção de um Plano de Preservação Digital (PPD), que seja um documento estratégico que operacionalize a política de preservação digital.

Segundo os autores, um PPD corresponde ao um documento de cunho estratégico que contenha políticas e procedimentos que orientem a constituição de estrutura técnica e organizacional, permitindo, dessa forma, preservar continuadamente documentos arquivísticos digitais por meio de ações realizadas sobre os objetos digitais (OD) que os compõem.

A utilidade do PPD, segundo Barbedo, Corujo e Sant' Ana (2011), destina-se a identificação de quais e de que forma as funcionalidades devem ser implementadas para manter a integridade e usabilidade dos documentos digitais ao longo do tempo.

Segundo Barbedo, Corujo e Sant'Ana (2011, p. 9),

O desenvolvimento de um Plano de Preservação Digital e a seleção das estratégias apropriadas, deve ser o resultado de um esforço de colaboração entre as unidades orgânicas referentes ao arquivo (gestão documental) e à informática (tecnologias da informação), com a participação de todas as unidades orgânicas afetadas pelo processo ou que produzam informação eletrônica.

Um PPD destina-se a qualquer organização que produza documentos arquivísticos digitais, que os mantenha em formato digital, tenham reconhecidas as necessidades de utilização operacional dessas informações que excedam sete anos de longevidade e que pretendam elaborar um planejamento que determine procedimento que reúnam condições materiais necessárias à preservação dos documentos.

Para a elaboração de um PPD, conforme a percepção de Barbedo, Corujo e Sant'Ana (2011), há alguns pré-requisitos a serem seguidos, tais como a aplicação de instrumentos de gestão de documentos (Plano de Classificação e o que eles compreendem como sendo Tabela de Seleção ou, para a terminologia brasileira, a Tabela de Temporalidade e destinação de documentos de arquivo.)

O Plano de Classificação, segundo os autores, permite otimizar a aplicação de um PPD, "na medida em que se apresenta como ferramenta 
de gestão de documento de arquivo" (BARBEDO; CORUJO; SANT'ANA, 2011, p. 12).

Dentre os objetivos de um Plano de Classificação para o um PPD, estão: perceber as relações entre os documentos arquivísticos digitais geridos pelos diferentes Sistemas de Informação (SI); assegurar a continuidade das terminologias dos documentos ao longo do tempo; facilitar a recuperação dos documentos de arquivo; definir os níveis de proteção e de acesso aos diferentes conjuntos documentais.

Segundo os autores um Plano de Classificação deve ser funcional, pois refletirá as atividades de uma determinada organização e resultará da análise das suas funções/ atividades, constituindo-se enquanto base crítica para a organização e recuperação de documentos

Já a Tabela de Seleção também constitui parte fundamental para a elaboração de um PPD, permitindo a definição de prazos de guarda e destinação de documentos (eliminação ou guarda permanente).

Barbedo, Corujo e Sant'Ana (2011) propuseram um levantamento de dados para a elaboração de um Plano de Preservação Digital aonde verifica, dentro da instituição pesquisada, aspectos relacionados à gestão dos arquivos, as características dos ficheiros, dos documentos arquivísticos digitais, bem como sua usabilidade, complexidade e escalabilidade. Além disso, a pesquisa permite identificar o processo avaliativo e definitivo de formatos, aplicações e soluções de armazenamento, bem como metadados, sistemas, custos, cronograma, controle e manutenção e redução de riscos.

A partir disso, segundo os autores, é possível seguir com a proposta metodológica para a elaboração de um PPD, contendo cinco fases: Apresentação da metodologia de elaboração do PPD; Identificação do SI; Avaliação arquivística do SI; Caracterização do SI e Planejamento de estratégia de preservação.

\section{Procedimentos metodológicos}

Segundo Silva (2005) há inúmeras formas de classificar as pesquisas, desde o ponto de vista da natureza, como pela forma de abordagem do problema, segundo seus objetivos e os procedimentos técnicos.

Do ponto de vista da natureza, a pesquisa pode ser classificada, segunda a autora, como básica, ou seja, que gera conhecimentos novos e úteis para o avanço de determinada ciência, mas sem uma aplicação prática prevista, ou classificada como aplicada, cuja qual gera conhecimentos para aplicação prática e direcionados para a resolução de problemas pontuais. Dos dois, a pesquisa básica envolve verdades e interesses universais, ao passo que a aplicada envolve verdades e interesses locais.

A pesquisa é classificada como aplicada, pois objetiva trazer reflexões à comunidade arquivística brasileira sobre os resultados obtidos pela pesquisa, melhorando sua atuação frente aos desafios da 
aplicabilidade das políticas de preservação digital nas instituições públicas brasileiras.

Quanto à abordagem do problema, essa pesquisa pode ser classificada como quali-quantitativa, pois consegue abranger a abordagem qualitativa e quantitativa em seus preceitos.

Uma pesquisa qualitativa, segundo retrata Chizzotti (2006, p. 28), surge do termo qualitativo, ou seja, que "implica uma partilha densa com pessoas, fatos e locais que constituem objetos de pesquisa, para extrair desse convívio os significados visíveis e latentes que somente são perceptíveis a uma atenção sensível". Para Silva (2005) uma pesquisa qualitativa considera a relação existente entre o mundo real e o sujeito, ou seja, entre o mundo objetivo e o mundo do sujeito, que não pode ser traduzido em números.

Já uma pesquisa quantitativa é aquela que traduz em números as opiniões e informações, tem como objetivo a classificação e análise. Esse formato, segundo Silva (2005, p. 20), "requer o uso de recursos e de técnicas estatísticas (percentagem, média, moda, mediana, desviopadrão, coeficiente de correlação, análise de regressão, etc)".

Considerando essas perspectivas, é possível dizer que a abordagem do problema dessa dissertação segue uma lógica quali-quantitativa, pois discute aspectos da realidade da preservação digital, bem como analisa dados estatísticos obtidos em levantamentos sobre a preservação digital no Brasil.

No que se refere aos objetivos, Silva (2005) propõe que a pesquisa pode ser classificada em: exploratória, proporcionando um aprofundamento daquilo que está sendo pesquisado com vistas a torna-lo explícito ou construir alguma hipótese, envolvendo, geralmente, levantamento bibliográfico e estudos de caso; descritiva, por meio de coleta de dados, seja questionário ou observação sistemática, com a descrição de características de determinada população, fenômeno ou estabelecimento de relações entre variáveis; explicativa, que busca explicar o porquê dos fenômenos que estão sendo pesquisados, seja por meio do método experimental (ciências naturais) ou observacional (ciências sociais).

Considerando as observações de Silva (2005), quanto aos objetivos, a pesquisa é classificada como exploratória, pois visa proporcionar maior familiaridade com as políticas de preservação digital no brasil e buscar hipóteses sobre sua aplicabilidade nas instituições públicas federais.

No que tange aos procedimentos técnicos, segundo Silva (2005), a pesquisa pode ser classificada como bibliográfica, documental, experimental, levantamento, estudo de caso, pesquisa "Expost-Facto" (experimental), pesquisa-ação (ação e resolução de um determinado problema) e pesquisa participante (interação entre pesquisadores e pesquisados).

Em relação aos procedimentos técnicos, foram realizadas: pesquisas bibliográficas sobre preservação digital, políticas de preservação digital e plano de preservação digital; levantamentos de dados com cerca de 55 
instituições públicas federais sobre a presença de políticas e planos de preservação digital no governo federal.

Os levantamentos de dados foram realizados durante o período de 12 de maio de 2016 a 10 agosto de 2016, por meio do Sistema Eletrônico do Serviço de Informação ao Cidadão (e-SIC), que é uma ferramenta desenvolvida para dar cumprimento às disposições previstas na Lei de Acesso à Informação ${ }^{2}$ a todos os órgãos públicos brasileiros. Foi proposta a realização do levantamento de dados em instituições públicas federais, seguindo alguns critérios, conforme o tipo de instituição: 9 Agências Reguladoras descritas no próprio e-SIC; 21 ministérios do poder executivo, abrangendo boa parte dos ministérios constantes no governo federal, à época; 11 universidades públicas federais que possuem o curso de Arquivologia, como uma forma de verificar se houve influência do curso na implantação de ações de preservação digital no âmbito de cada universidade; 3 autarquias públicas federais, escolhidas de forma aleatória; e 11 empresas estatais que de alguma forma estejam desenvolvendo ações de gestão documental.

\section{Análise e discussão dos resultados}

Complementando a pesquisa de Innarelli (2015), que identificava a presença de políticas de preservação digital em algumas organizações brasileiras como forma de contribuir para a sustentabilidade das ações práticas de gestão da preservação de documentos arquivísticos digitais, foi realizada uma pesquisa que teve como propósito identificar a presença de políticas de preservação digital e de PPD's nas instituições.

Ao longo do período de 12 de maio de 2016 a 10 de agosto de 2016 foi realizada uma pesquisa sobre a existência de plano de preservação digital ou pelo menos uma política de preservação digital que siga parâmetros estabelecidos pelo Conarq.

A pesquisa foi desenvolvida via Sistema Eletrônico do Serviço de Informação ao Cidadão, o e-SIC, e o público-alvo foram: 09 (nove) agências reguladoras do Brasil (Agência Nacional de Águas (ANA), Agência Nacional de Aviação Civil (ANAC), Agência Nacional de Cinema (ANCINE), Agência Nacional de Vigilância Sanitária (ANVISA), Agência Nacional de Energia Elétrica (ANEEL), Agência Nacional de Transportes Terrestres (ANTT), Agência Nacional de Petróleo, Gás Natural e Biocombustíveis (ANP), Agência Nacional de Saúde Complementar (ANS) e Agência Nacional de Telecomunicações (ANATEL); 21 (vinte e um) Ministérios (Ministério da Agricultura, Pecuária e Abastecimento (MAPA), Ministério de Ciência e Tecnologia e Inovação (MCTI), Ministério da Cultura (MinC), Ministério da Defesa (MD), Ministério da Fazenda (MF), Ministério da Integração (MI), Ministério da Justiça (MJ), Ministério da Previdência Social (MPS), Ministério da Saúde (MS), Ministério das Cidades

\footnotetext{
${ }^{2}$ Lei n. 12.527 , de 18 de novembro de 2011, que regula o acesso a informações previsto no inciso XXXIII do art. 50, no inciso II do § 30 do art. 37 e no § 20 do art. 216 da Constituição Federal; altera a Lei no 8.112, de 11 de dezembro de 1990; revoga a Lei no 11.111, de 5 de maio de 2005, e dispositivos da Lei no 8.159 , de 8 de janeiro de 1991; e dá outras providências.
} 
(MCidades), o Ministério das Comunicações $(M C)^{3}$, Ministério das Relações Exteriores (MRE), Ministério de Minas e Energia (MME), Ministério do Desenvolvimento Agrário (MDA), Ministério do Desenvolvimento, Indústria e Comércio (MDIC), Ministério do Meio Ambiente (MMA), Ministério do Planejamento, Orçamento e Gestão (MP), Ministério do Trabalho e Emprego (MTE), Ministério dos Transportes (MT), Portos e Aviação Civil (MT), Ministério do Turismo (MTur)); 11 (onze) universidades públicas federais (Fundação Universidade de Rio Grande (FURG), Universidade de Brasília (UnB), Universidade Federal do Estado do Rio de Janeiro (UNIRIO), Universidade Federal da Bahia (UFBA), Universidade Federal de Minas Gerais (UFMG), Universidade Federal de Santa Catarina (UFSC), Universidade Federal de Santa Maria (UFSM), Universidade Federal do Amazonas (UFAM), Universidade Federal do Espírita Santo (UFES), Universidade Federal do Rio Grande do Sul (UFRGS) e Universidade Federal do Fluminense (UFF)); 03 (três) autarquias (Banco Central do Brasil (BACEN), Arquivo Nacional (AN) e Advocacia-Geral da União $(A G U)$ ); e 11 (onze) empresas estatais do governo federal (Agência Brasileira Gestora de Fundos Garantidores e Garantias (ABGF), Banco da Amazônia (BASA), Banco do Nordeste do Brasil (BNB), Eletrobrás, Embrapa, Empresa de Correios e Telégrafos (ECT), Infraero, Petrobrás, Serviço Federal de Processamento de Dados (SERPRO), a Empresa de Trens Urbanos de Porto Alegre (TRENSURB) e Banco do Brasil (BB)).

Ao todo foram 55 (cinquenta e cinco) instituições públicas brasileiras que participaram da pesquisa, conforme o Gráfico 1, sendo, por tanto, 9 (nove) agências reguladoras, 21 (vinte e um) ministérios, 11 (onze) universidades públicas federais com curso de graduação em arquivologia, 3 (três) autarquias e 11 (onze) empresas estatais do governo federal.

Gráfico 1 - Âmbito da pesquisa sobre Preservação Digital no Brasil

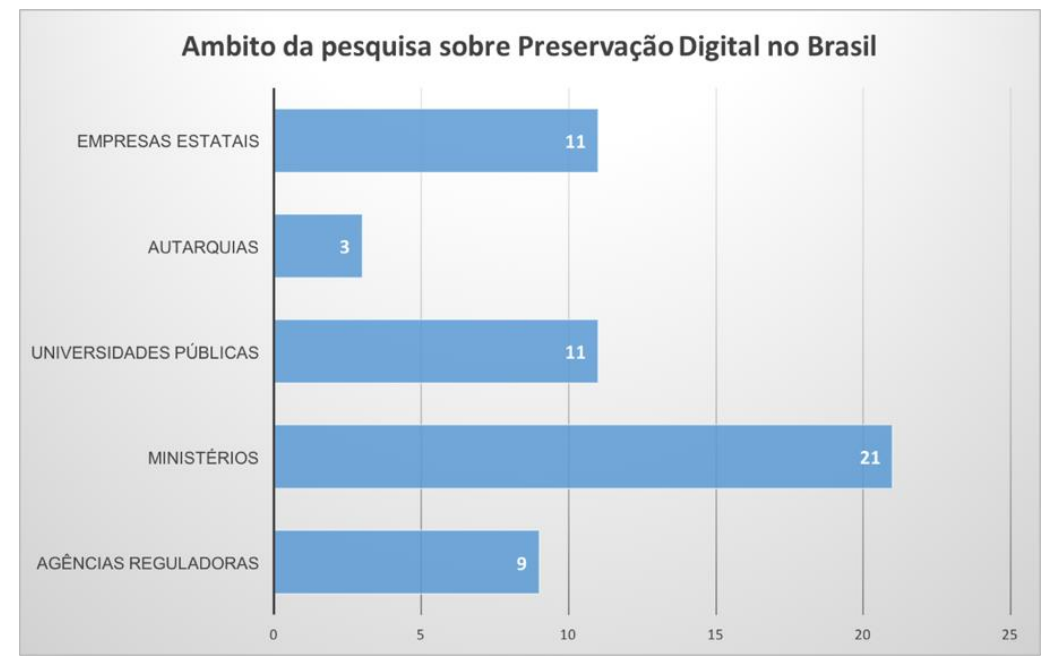

Fonte: Elaboração própria.

\footnotetext{
${ }^{3}$ No momento da pesquisa este órgão acabava de ser extinto, por força da Medida Provisória n. ${ }^{\circ} 726$, de 12 de maio de 2016, que mais tarde a referida Medida foi convertida na Lei n. ${ }^{0} 13.341$, de 29 de setembro de 2016, mas, na prática continuava funcionando, agora vinculado ao MCT.
} 
Já no Gráfico 2 estão dados percentuais sobre a presença de política de Preservação Digital e PPD.

Gráfico 2 - Preservação Digital em instituições públicas federais

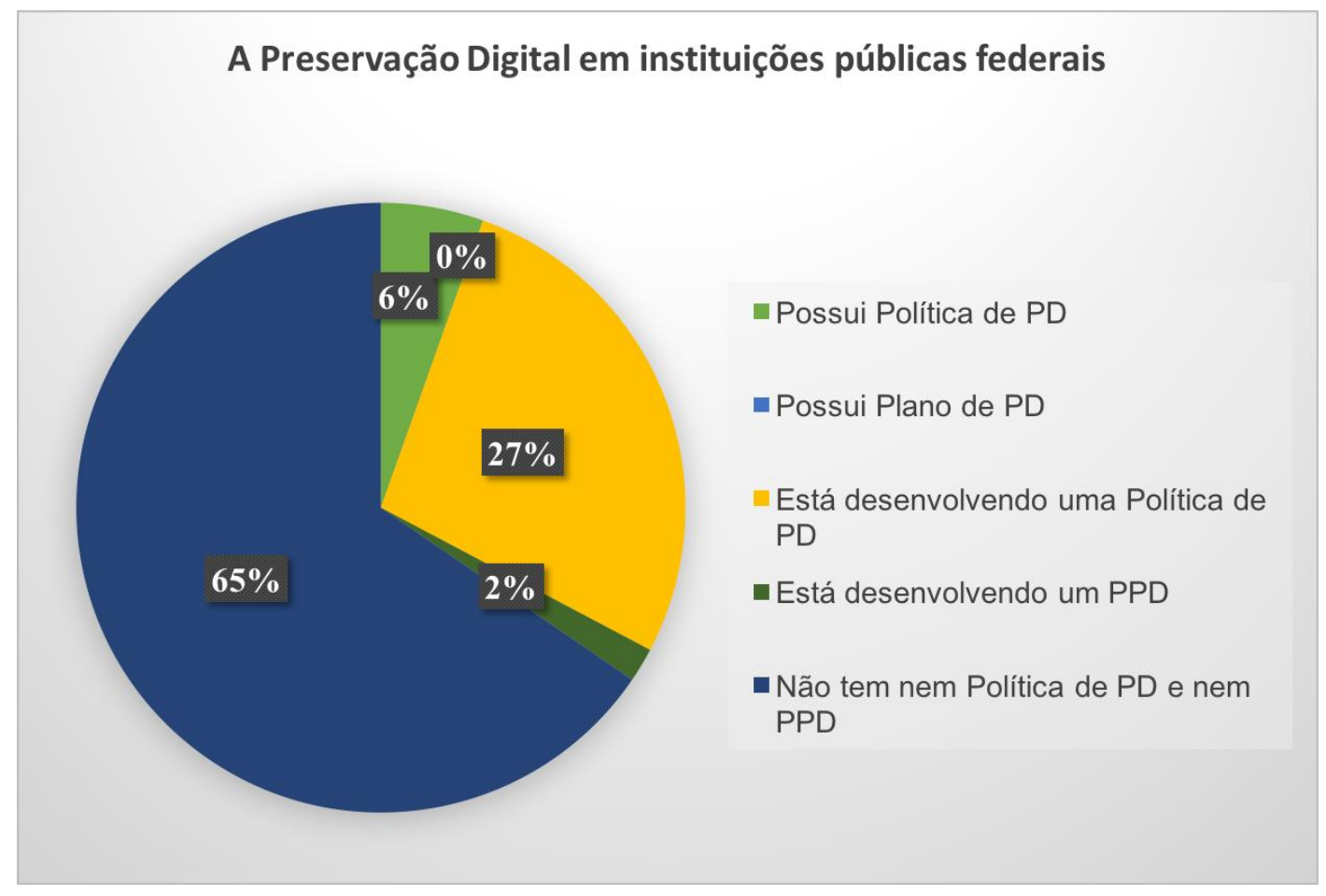

Fonte: Elaboração própria.

Desse total, conforme o Gráfico 2, foi constatado que somente $6 \%$ possui uma política de PD, ou seja, 3 (três) das 55 (cinquenta e cinco) instituições públicas federais, a ANA, a AGU, o AN.

A ANA informou que possui uma política para as atividades de digitalização, que tem como objetivo garantir o acesso e a preservação do patrimônio arquivístico digital, e que foi instituída por meio da Resolução no 1.774, de 21 de novembro de 2014. Segundo informado pela instituição, a referida Resolução tomou como base as orientações emanadas pela Resolução no 31, de 28 de abril de 2010, do Conarq, que dispõe sobre uma série de recomendações para a Digitalização de Documentos Arquivísticos Permanentes. A instituição esclareceu também que faz parte do seu planejamento (2016-2019) o aperfeiçoamento da sua gestão documental e da preservação da sua memória institucional, momento em que se dará continuidade às atividades de preservação digital de seus documentos arquivísticos.

A AGU informou que segue os mesmos parâmetros estabelecidos pelo Conarq e a CTDE no que tange à preservação digital de seus arquivos e ainda citaram que se basearam nas exigências técnicas elencadas nas Resolução no 25, de 27 de abril de 2007 e de no 32, de 17 de maio de 2010, ambas tratando sobre o "Modelo de Requisitos para os Sistemas Informatizados de Gestão Arquivística de Documentos (SIGAD's)", o eARQ Brasil. Conforme elucida Flores (2016) a cadeia de custódia é composta pelos SIGAD's e os sistemas de informação para a descrição e 
armazenamento de documentos de arquivo permanentes, sendo que os primeiros são equivalentes às duas fases iniciais do ciclo de vida dos documentos (corrente e intermediária) e não da destinação final (guarda permanente). Por tanto, conclui-se que o sistema que a AGU utiliza gerencia arquivos correntes e intermediários e não arquivos permanentes, não tendo, ainda, uma política que abranja toda a cadeia de custódia para fins de preservação digital.

O Arquivo Nacional informou que há um Programa Permanente de Preservação e Acesso a Documentos Arquivísticos Digitais, o AN Digital, criado no dia 25 de março de 2010, e que possui, em seu cronograma de trabalho, desde então, uma série de Projetos (1 ao 13) com ações voltadas desde a visitas técnicas às instituições que fazem preservação digital, em um momento de prospecção, até a implantação da metodologia de gerenciamento de projetos, em três etapas de trabalho, constituindo-se uma parte da Gestão do Programa.

Além desse trabalho, o AN citou que o Conarq, que é vinculado a ele, elaborou em 2004 uma Carta para a Preservação do Patrimônio Arquivístico Digital que evidencia uma série de desafios sobre a temática de instituições públicas brasileiras e estabelece uma série de estratégias e políticas para a preservação digital.

A partir disso, o Conarq, conforme descrito no Programa, aprovou outras resoluções sobre documentos arquivísticos digitais, tais como a no 20, de 16 de julho de 2004, que "dispõe sobre a inserção dos documentos digitais em programas de gestão arquivística de documentos dos órgãos e entidades integrantes do Sistema Nacional de Arquivos"; a no 24, de 3 de agosto de 2006, que "estabelece diretrizes para a transferência e recolhimento de documentos arquivísticos digitais para instituições arquivísticas públicas"; e a no 25, de 27 de abril de 2007, que "dispõe sobre a adoção do Modelo de Requisitos para Sistemas Informatizados de Gestão Arquivística de Documentos", que hoje constitui o e-ARQ Brasil.

Conforme os resultados obtidos pelo uso do e-SIC duas outras instituições alegaram possuir uma Política de Preservação Digital, mas conforme a análise foi constato o oposto. A primeira delas é o MI, que havia encaminhado uma minuta de Portaria, com um número 29, de 3 de setembro de 2015, que instituiria a política de PD do referido órgão, com base na Lei de Acesso à Informação (LAI), aprovada pela Lei no 12.527, de 18 de novembro de 2011, na Carta para Preservação do Patrimônio Arquivístico Digital e no e-ARQ Brasil. No entanto, ao realizar a pesquisa sobre a referida Portaria no site do MI verificou-se a inexistência da referida Portaria com esse assunto, pois a Portaria no 29, de 10 de março de 2015, além de ter uma data diferente, não trata sobre o mesmo assunto. No site do referido órgão há somente um Plano de Integração dos Serviços à Plataforma de Cidadania Digital, mas não uma Politica de Preservação Digital, e que vai descrever a estratégia do MI em transformação digital dos serviços públicos, ms não trazendo em seu escopo e metodologia alguma referência do Arquivo Nacional e do CONARQ. 
Já o MTE, por meio da Coordenação de Documentação e Informação (CDIN), informou que o referido órgão público federal possui um PPD e que segue as diretrizes estabelecidas pelo Conarq (Resolução no 39, de 29 de abril de 2014, que foi atualizada pela Resolução no 43, de 4 de setembro de 2015), para a gestão dos seus documentos digitais. Além disso, a CDIN está projetando a criação de um repositório digital para o Ministério.

No entanto, além de não ter enviado o PPD o órgão citou a Resolução no 39/2014, do CONARQ como parte da sua política. A Resolução, no entanto, além de tratar diretamente da política de $\mathrm{PD}$, pois ela recomenda a implementação de RDC-Arq's nos órgãos e entidades integrantes do Sistema Nacional de Arquivos (SINAR), considera que é dever das instituições arquivísticas estabelecera sua política de preservação e de preservação do patrimônio arquivístico digital.

Constata-se, por tanto, que o órgão não possui política e nem PPD, pois ao invés de ter encaminhado os documentos que comprovam a existência de uma política de PD, e, com isso, um PPD, encaminhou uma resolução que orienta a criação de políticas de preservação e preservação do patrimônio arquivístico digital, e não a sua própria política.

Do total das instituições pesquisadas, deduz-se que $27 \%$ delas, ou seja, 15 (quinze) instituições públicas federais (ANP, ANCINE, ANEEL, BB, SERPRO, MAPA, MJ, MPS, MCidades, MC, MME, UnB, UFBA, UFMG e UFSM), estão desenvolvendo alguma política de preservação digital, e, consequentemente, nenhuma desenvolveu um PPD.

A ANCINE afirmou que há uma previsão de ser iniciado ainda neste ano a elaboração da Política de Preservação de Acervo Digital, pois em outubro de 2015 foi iniciado o processo eletrônico na Agência com o uso da ferramenta $\mathrm{SEI}^{4}$ (Sistema Eletrônico de Informações). Neste caso, não foi informado se a política seguirá ou não as orientações do Conarq.

A ANEEL, em resposta à pesquisa, afirmou que não possui um PPD, mas que está em fase de elaboração do normativo. A referida instituição também não informou se esse processo de elaboração da política está sendo embasada nas orientações emanadas pelo Conarq.

Conforme informado pelo BB há uma espécie de controle da preservação digital que é suportada pelo parque tecnológico atual e futuro, utilizando de estratégias de investimento de Tecnologias da Informação. Depreende-se que essa seja uma política de preservação digital utilizada pelo referido Banco, mas que ainda não respeite às perspectivas e orientações emanadas pelo Conarq.

No caso do SERPRO, apesar de ter sido criado para o processamento de dados do governo federal, considera relativamente recente o assunto preservação digital, coincidindo com a afirmativa de Innarelli (2015) sobre a carência de instituições que conhecem políticas de PD. A instituição afirmou também que, apesar de não possuir um PPD, ele dispõe de uma

\footnotetext{
O SEI é um sistema de gestão de processos e documentos eletrônicos e foi desenvolvido pelo Tribunal Regional Federal da 4a Região (TRF4), por meio do projeto Processo Eletrônico Nacional (PEN), possuindo um conjunto de módulos e funções que contribuem para a eficência administrativa.
} 
política de gestão arquivística de documentos, retratando o quê tem que ser realizado, mas não no o "como fazer".

No entanto, a Resolução interna do SERPRO que trata da política de gestão arquivística de documentos, aprovada recentemente (07 de abril de 2016), versa sobre a organização de arquivos e o gerenciamento das informações contidas nos documentos, independente do suporte. 0 embasamento técnico e legislativo segue as recomendações do Conarq, tanto para os documentos analógicos quanto digitais.

Outro ponto bastante oportuno está relacionado com a gestão de documentos observada pelo artigo $3^{\circ}$ da Lei 8.159, de 1991 (produção, tramitação, uso, avaliação, arquivamento em fase corrente e intermediária e eliminação ou recolhimento para guarda permanente).

Além dessa perspectiva, o SERPRO, por meio dessa Resolução, inicia uma discussão arquivística sobre confiabilidade, autenticidade, acessibilidade, para que os documentos possam estar disponíveis e compreensíveis ao longo do tempo, compreendendo-se, por tanto, a formação de uma percepção sobre relevância da cadeia de custódia, seguindo a representação de Flores (2010) a partir da percepção de Jenkinson (1922).

A ANP afirmou que mesmo não possuindo um PPD há um projeto em andamento que, além do gerenciamento eletrônico do processo administrativo da instituição, há ações desenvolvidas pela Coordenadoria de Documentação e Informação na conscientização e implementação de outras ferramentas que possibilitem a segurança da informação digital e a manutenção e preservação de documentos digitais.

O MAPA respondeu dizendo que estão utilizando documentos digitais a poucos meses e estão iniciando a construção de políticas de $P D$, não possuindo, com isso, um PPD. Essa instituição também não informou se o estudo para a construção da política está sendo embasado nas orientações emanadas pelo Conarq.

O MJ destacou, por meio de memorando, que mesmo com a ausência de política de PD o órgão está adotando medidas que asseguram que os documentos arquivísticos digitais estão armazenados em um banco de dados do SEI, de forma acessível, compreensível, autêntica e íntegra até a sua transferência para um Repositório Digital Confiável. A partir dessa perspectiva, não se sabe se o órgão adotou as orientações emanadas pelo Conarq quanto à $\mathrm{PD}$, mas certamente aquelas elaboradas pela área tecnológica do TRF da $4^{a}$ região, haja vista que o SEI é da autoria desse referido tribunal.

O MPS informou que a política ou PPD está em fase de elaboração e já foi criado um Comitê Deliberativo para implementar o Projeto de Gestão da Informação Corporativa, no âmbito do MPS e de suas entidades, bem como publicação de duas outras Portarias, uma em 2013 ( $n^{\circ} 157$ ) e em 2015 ( $n^{\circ}$ 368), aprovando módulos para o trabalho de gestão da informação e documentação. O Manual de Gestão da Informação e Documentação, o MGID, elaborado pelo MPS, não foi encaminhado e por isso não foi possível identificar se as orientações se baseiam na política emanada pelo Conarq. 
O MCidades informou que já está trabalhando para implantar uma política de preservação, compreendendo sua relevância, não sendo possível informar se essa política segue orientações emanadas pelo Conarq quanto à política de PD.

O MC, que naquele momento da pesquisa estava sendo extinto, respondeu que estava desenvolvendo estudos com vistas à criação de uma política de preservação de documentos digitais e consideravam tanto a teoria e técnicas da Tecnologia da Informação (TI) quanto da Arquivística. O embasamento utilizado pelo Ministério, conforme elucidado pelo Chefe de Serviço de Arquivo e Biblioteca, levava em consideração os documentos elaborados pela CTDE ("Diretrizes para a presunção de autenticidade de documentos arquivísticos digitais", oriundas da Resolução no 37, de 19 de dezembro de 2012, e "Diretrizes para a implementação de repositórios digitais confiáveis de documentos arquivísticos", oriundas da Resolução no 43, de 29 de abril de 2014), bem como o Projeto InterPARES e a norma ISO TC 46/SC 11/WG 7 sobre Preservação Digital em Arquivos. No que tange à parte da TI o Ministério afirmou que realiza uma rotina de backups de dados digitais, o que coaduna com a reflexão de Innarelli (2015) sobre a relevância dessa atividade como parte do processo de construção de uma política de PD.

O MME considerou que também está em fase de elaboração de uma política de PD que, apesar de não possuir um PPD, o Ministério, por meio da Resolução no 39, está reformulando sua norma interna que tem como objetivo regular o tratamento documental em meio eletrônico, visando a preservação dos documentos digitais.

A UnB respondeu à pesquisa informando o processo de elaboração da política arquivística está em elaboração e que contemplará a preservação de documentos arquivísticos digitais, sendo que alguns procedimentos relativos ao uso e preservação de documentos arquivísticos digitais são orientados por um Manual de Gestão de Documentos da referida universidade. Esses procedimentos, por sua vez, são baseados na legislação arquivística brasileira.

Outra universidade que afirmou estar em fase de elaboração da política é a UFBA, que informou que há, inclusive, um convênio com o MCT/IBICT para a preservação digital.

A UFBA realizou um acordo de cooperação técnica com o MCT/IBICT para a implementação de um sistema de informação denominado LOCKSS, que permite a integração com a Rede Brasileira de Serviços de Preservação Digital (CARINIANA), mas não especificou exatamente o que o sistema faz.

Essa Rede CARINIANA, segundo relata o próprio IBCT (2016), surgiu com o objetivo de realizar a preservação digital de documentos eletrônicos brasileiros, garantindo o acesso continuado a longo prazo dos conteúdos armazenados em ambiente digital. Segundo o site do sistema de informação (LOCKSS, 2016), o LOCKSS é utilizado para a preservação digital em ambientes de biblioteca e não especificamente de arquivos, 0 que traz algumas dúvidas sobre o controle da cadeia de custódia, proposta por Jenkinson (1922). 
A UFMG informou que possui três diretorias envolvidas no tratamento e preservação da informação, a Diretoria de Arquivos Institucionais, a Diretoria de Tecnologia da Informação e a Diretoria de Governança Informacional, e que as discussões sobre a criação e desenvolvimento de um PPD estão sendo iniciadas. Não foi possível afirmar que a referida universidade baseará seus estudos na política de PD proposta pelo Conarq.

E por fim, a UFSM informou que em 2014 foi instituída uma Comissão que realizará estudos para a implementação de um projeto de gestão, preservação e acesso a longo prazo aos documentos arquivísticos digitais da referida instituição, além de referir que a política que é tema de dissertação de mestrado em Patrimônio Cultural da UFSM por uma das arquivistas do local. Não foi possível identificar se a referida universidade baseará seus estudos na política de PD proposta pelo Conarq.

Deduz-se, por tanto, que do total dessas instituições que estão elaborando suas políticas de PD, cerca $40 \%$ delas segue orientações emanadas pelo Conarq para o desenvolvimento de suas ações, conforme mostra o Gráfico 3. As demais instituições, cerca de $60 \%$, não mencionaram se seguem as orientações do Conarq para a elaboração de suas políticas de PD.

Gráfico 3 - Percentual de instituições que se baseiam em políticas do Conarq

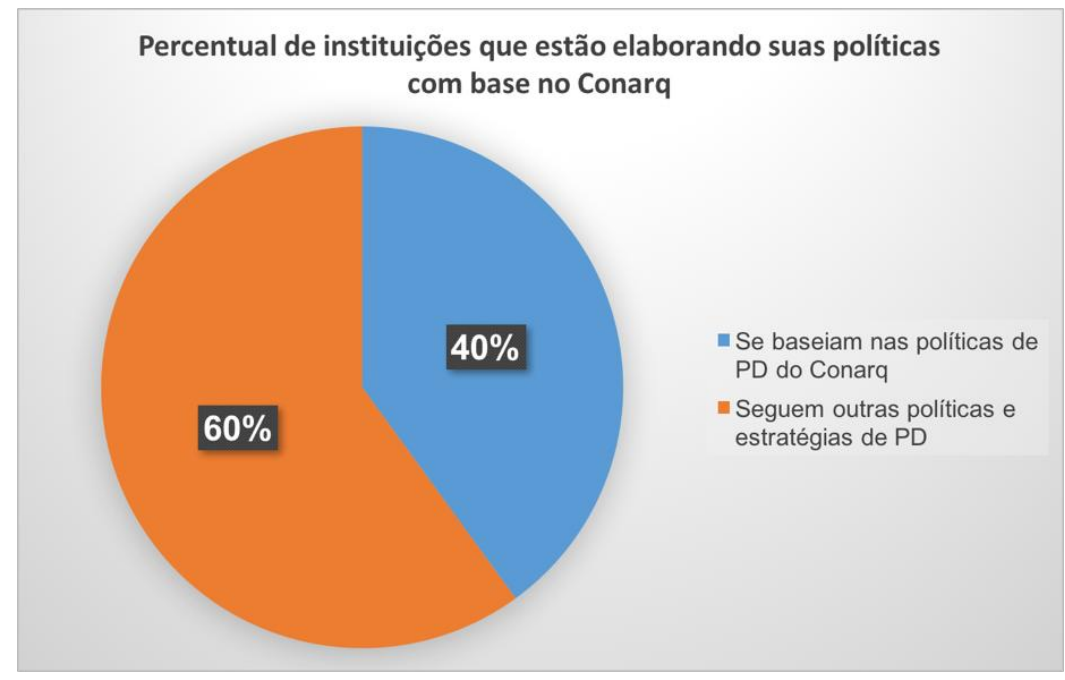

Fonte: Elaboração própria.

Considerando os dados expressados no Gráfico 2, que mostra que cerca de $65 \%$, ou seja, 37 instituições entrevistadas não possuem nem política e nem PPD, é possível perceber, a partir da análise, que desse total, cerca de $21 \%$ estão desenvolvendo ações de Gerenciamento Arquivístico de Documentos, $19 \%$ estão desenvolvendo ações de Gestão Eletrônica de Documentos e 14\% utilizam o Sistema Eletrônico de Informações (SEI). As demais instituições (46\%) não informaram se desenvolvem outras ações. Esses dados são expressados no Gráfico 4. 


\section{Gráfico 4 - Percentual de instituições que desenvolvem outras ações}

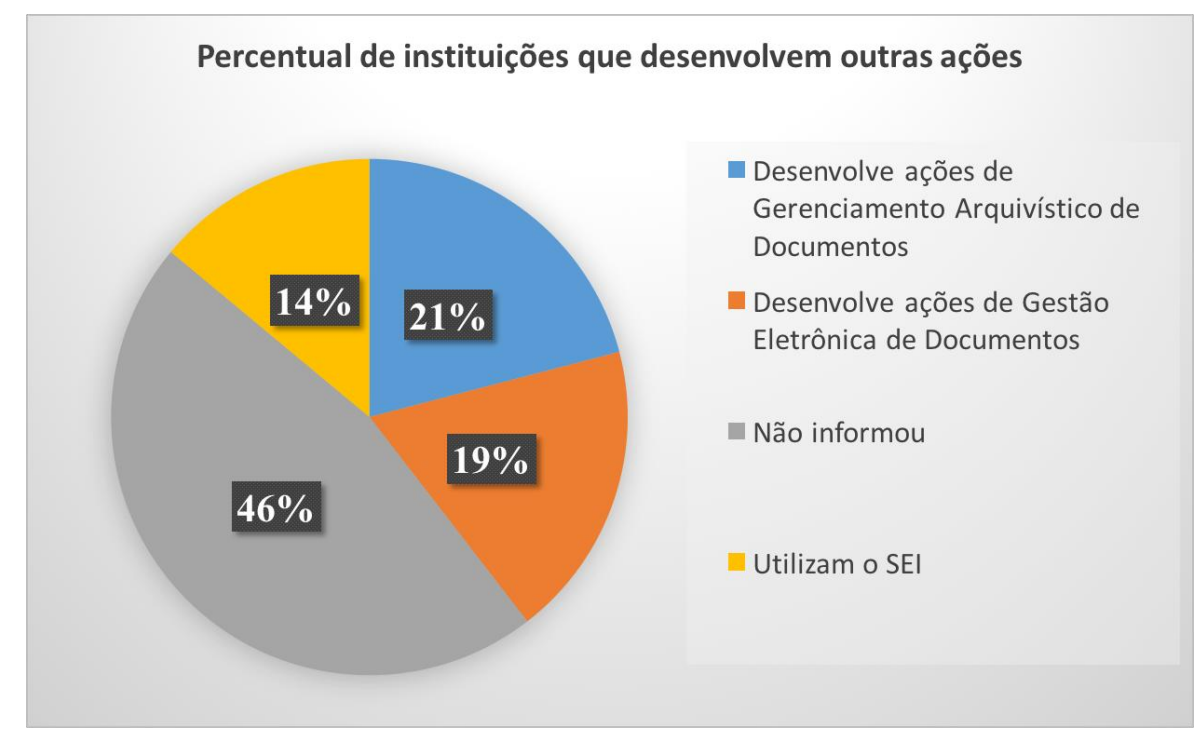

Fonte: Elaboração própria.

A ABGF informou que mesmo sendo uma Agência nova, pois foi criada em 2013 e que só iniciou efetivamente suas atividades em julho de 2014, está em fase de estudos e elaboração da política de gestão de arquivos da empresa, não havendo ainda a definição de diretrizes e metodologias para a preservação digital de seus documentos.

A ANS, ANATEL, O ECT, a EMBRAPA, o MDA e o MinC informaram que estão utilizando o SEI, o Sistema Eletrônico de Informações, para o gerenciamento eletrônico de suas informações. Cabe salientar que esse sistema, apesar de constituir em uma Política Pública disseminada pelo Governo Federal, por meio do TRF4, conforme citado anteriormente, ainda não segue diretrizes do Conarq quanto às políticas de Gestão de Documentos, muito menos contribui para a perspectiva apresentada por Flores (2010) sobre a noção de cadeia de custódia. A ANS também informou que possui Plano de Classificação e Tabela de Temporalidade e destinação de documentos de arquivo, encontrando-se em fase de aprovação da Comissão Permanente de Avaliação de Documentos.

O BACEN informou que possui um sistema de processo eletrônico que está em fase de desenvolvimento, obedecendo às regras do e-Arq Brasil e às orientações do e-PING ${ }^{5}$, e que até o momento, em razão disso, não foi elaborada a Política e o PPD. Considerou, com sua afirmativa, que o uso desse sistema facilitará o acesso às informações, em razão do gerenciamento de formatos e de mídias de armazenamento que o sistema propiciará.

A INFRAERO informou que digitaliza seus documentos oficiais, inserindo-os em um sistema de gestão eletrônica de documentos. Não foi possível identificar se o referido sistema segue, pelo menos, orientações emanadas pelo Conarq para a gestão arquivística de documentos.

\footnotetext{
5 O e-PING, segundo o Ministério do Planejamento, Orçamento e Gestão (2014), são "Padrões de Interoperabilidade de Governo Eletrônicod Brasil e que constituem em um conjunto mínimo de premissas, políticas e especificações técnicas que regulamentam a utilização da Tecnologia de Informação e Comunicação (TIC) na interoperabilidade de serviços de Governo Eletrônico."
} 
O MCTI é um dos Ministérios que possui um Sistema de Gerenciamento Eletrônico de Documentos baseado nas recomendações do e-Arq Brasil, seguindo os critérios de confiabilidade, autenticidade e acessibilidade adotados pelo Conarq.

O MD informou que, apesar de não possuir um PPD, desenvolve ações no que se refere à temporalidade dos documentos de acordo com a tabela de temporalidade, conforme as Resoluções no 14, de 24 de outubro de 2001, e a de no 21, de 4 de agosto de 2004, do Conarq. Informou também que possui um Plano de Classificação e uma Tabela de Temporalidade da Área-Fim da instituição e que realiza atividades de backup tradicional de toda a base de dados, bem como os arquivos envolvidos na aplicação, e são armazenados em mídia e arquivados em cofre protegido de eventuais sinistros.

O MP informou que apesar de não possuir um PPD segue parâmetros estabelecidos pelo Conarq no que tange à preservação de documentos digitais.

O MT informou que não foi desenvolvido até o momento nenhum programa ou sistema que verse sobre a preservação de documentos arquivísticos digitais e que estão em fase de elaboração de um trabalho de organização do acervo documental convencional. Percebe-se que, apesar de não informado, a referida instituição também faz uso do SEI na gestão eletrônica de suas informações.

O MTE, conforme observado anteriormente, não deixou claro se as referências utilizadas (Resoluções do Conarq) resultaram na criação de ações de Gerenciamento Arquivístico de Documentos, o que fica claro, somente, o uso para a gestão de documentos digitais e a criação de um repositório digital para o Ministério. Dessa forma, conclui-se que o MTE não foi claro que se tem ou não alguma ação efetiva de Gerenciamento Arquivístico de Documentos, mas sim em Gestão de Documentos Eletrônicos.

A UFES informou que não possui um PPD, mas políticas e diretrizes sobre Tecnologias da Informação que podem contribuir para a formação de uma política de preservação digital se baseada nas diretrizes emanadas pelo Conarq.

A UFSC informou que não possui nem política e nem um PPD, mas que mantém suas informações armazenadas sem a realização de nenhum descarte. Apesar não ter informado, infere-se que a referida universidade não possui nenhuma ação voltada à gestão documental, à luz da arquivística contemporânea.

A UNIRIO informou que já possui uma tradição na gestão de seus documentos e que estão baseadas na legislação arquivística em vigor, emanadas pelo Conarq. Além disso, informou que estão buscando condições para a implementação de um sistema de gestão eletrônica de documentos capaz de incluir, futuramente, os Documentos Digitais. A universidade informou também que possui uma política de backup do seu sistema (Sistema de Informação Eletrônica - SEI), que é utilizado para o gerenciamento de processos. 
Os outros órgãos que não possuem Política de Preservação Digital e PPD não informaram ou não foram claros suficientes para que fosse possível constatar se há ações de gerenciamento arquivísticos de documentos, de gestão de documentos eletrônicos ou se usam o SEI.

\section{Considerações finais}

Diante desse contexto atual, depreende-se que a afirmativa de Innarelli (2015) sobre a carência de políticas de preservação digital no Brasil alcança também parte da esfera de grandes instituições públicas federais, como Agências Reguladoras, Ministérios e empresas estatais.

Deduz-se que esse indicador é um alerta para a comunidade arquivística e o próprio Arquivo Nacional, pois a difusão das ações sobre Preservação Digital do Arquivo Nacional e do Conarq, no governo federal, ainda não conseguiu alcançar a presença de PPD's em boa parte das instituições públicas federais.

Em alguns casos, conforme evidenciado na pesquisa, as políticas de preservação digitais estão em fase de desenvolvimento, não sendo presente em boa parte das instituições entrevistadas, mesmo já cientes da política nacional de arquivos para o âmbito dos documentos analógicos, confirmando também a hipótese levantada por Innarelli (2015) sobre a evolução desse entendimento por parte das organizações atuais.

Ao que parece é que boa parte das instituições entrevistadas está focada em dar acesso às informações que produz e acumula em sua estrutura tecnológica (sistemas de informação e demais plataformas), expandindo-se gradativamente o uso do SEI nas esferas públicas do governo.

No entanto, o referido sistema, conforme mencionado, carece de metadados básicos que contribuam para que a classificação e avaliação documental possam ser realizadas durante o registro dos seus acervos, de tal forma que seja possível identificar quais os que serão eliminados e os que serão objeto de preservação digital. Sem esses elementos, é difícil enxergar a aplicabilidade das políticas do Conarq dentro das referidas instituições entrevistadas, no que tange aos seus documentos digitais.

Deduziu-se também que há um distanciamento do Conarq para com a realidade das referidas instituições, no que tange a aplicabilidade de suas próprias diretrizes no âmbito dos documentos arquivísticos digitais, já que a realidade, em boa parte dos casos, é de uso de estratégias que ainda não abrangem a política arquivística de preservação digital. A ausência de notas técnicas emitidas pelo Conarq sobre a inobservância das diretrizes nacionais quanto às políticas arquivísticas de documentos digitais parece ser um forte indício desse distanciamento, contribuindo para que as referidas instituições sigam seus próprios entendimentos acerca do uso e proteção de seus acervos.

Torna-se imprescindível o desenvolvimento efetivo de ações de sensibilização e conscientização das lideranças das referidas instituições quanto à observação da legislação e orientações emanadas pelo Arquivo 
Nacional e o Conarq, de tal forma que seja possível reduzir os riscos eminentes sobre a preservação da memória nacional.

\section{Referências}

AGÊNCIA NACIONAL DE ÁGUAS (BRASIL). Resolução no 1774, de 21 de novembro de 2014. Estabelece a "Política para digitalização, captura, armazenamento e segurança de documentos com o objetivo de garantir o acesso e a preservação do patrimônio arquivístico digital da Agência Nacional de Águas - ANA". Disponível em: $<$ http://arquivos.ana.gov.br/resolucoes/2014/1774-2014.pdf>. Acesso em: 14 jan. 2016.

ARELlANO, M. A. Preservação de documentos digitais. Ci. Inf., Brasília, v. 33, n. 2, p. 15-27, maio/ago. 2004.

ARELLANO, M. A. Preservação digital e os profissionais da informação. Data Grama Zero, Revista de Ciência da Informação, v. 7, n. 5, p. 1-9, out. 2006.

BARBEDO, F.; CORUJO, L.; SANT'ANA, M. Recomendações para a produção de planos de preservação digital. Direção Geral de Arquivos DGARG, 2011. v. 2.1 Disponível em: <http://arquivos.dglab.gov.pt/wpcontent/uploads/sites/16/2014/02/Recomend_producao_PPD_V2.1.pdf > . Acesso em: 15 nov. 2015.

BOERES, S. A. de A.; CUNHA, M. B. da. Competências básicas para os gestores de preservação digital. Ci. Inf., Brasília, DF, v. 41, n. 1, p. 103113, jan./abr. 2012.

BRASIL. Lei 8.159, de 8 de janeiro de 1991. Dispõe sobre a Política Nacional de Arquivos Públicos e Privados e dá outras providências. Disponível em: <http://www.planalto.gov.br/ccivil_03/LEIS/L8159.htm>. Acesso em: 14 jan. 2016.

BRASIL. Lei no 12.527, de 18 de novembro de 2011. Regula o acesso a informações previsto no inciso XXXIII do art. 50, no inciso II do $\S 3^{\circ}$ do art. 37 e no $\S 20$ do art. 216 da Constituição Federal; altera a Lei no 8.112, de 11 de dezembro de 1990; revoga a Lei no 11.111 , de 5 de maio de 2005 e dispositivos da lei no 8.159, de 8 de janeiro de 1991; e dá outras providências. Disponível em: <http://www.planalto.gov.br/ccivil_03/_ato20112014/2011/lei/l12527.htm>. Acesso em 14 jan. 2016.

BRASIL. Lei no 13.341, de 29 de setembro de 2016. Altera as Leis nos 10.683, de 28 de maio de 2003, que dispõe sobre a organização da Presidência da República e dos Ministérios, e 11.890, de 24 de dezembro de 2008, e revoga a Medida Provisória no 717, de 16 de março de 2016. Disponível em: <http://www.planalto.gov.br/CCiVil_03/_Ato20152018/2016/Lei/L13341.htm>. Acesso em: 14 jan. 2016. 
CHIZZOTTI, A. Pesquisa qualitativa em ciências humanas e sociais. Petrópolis, RJ: Vozes, 2006.

CONSELHO NACIONAL DE ARQUIVOS (CONARQ). Carta para preservação do patrimônio arquivístico digital. Rio de Janeiro: Arquivo Nacional, 2005. Disponível em: <http://Conarq.Conarq.arquivonacional.gov.br/images/publicacoes_textos /Carta_preservacao.pdf>. Acesso em: 14 jan. 2016.

CONSELHO NACIONAL DE ARQUIVOS (CONARQ). Resolução no 20, de 16 de julho de 2004. Dispõe sobre a inserção dos documentos digitais em programas de gestão arquivística de documentos dos órgãos e entidades integrantes do Sistema Nacional de Arquivos. Disponível em: <http://www.conarq.gov.br/resolucoes-do-conarq/262-resolucao-n-20,de-16-de-julho-de-2004.html>. Acesso em: 16 jan. 2016.

CONSELHO NACIONAL DE ARQUIVOS (CONARQ). Resolução no 24, de 3 de agosto de 2006. Estabelece diretrizes para a transferência e recolhimento de documentos arquivísticos digitais para instituições arquivísticas públicas. Disponível em: <http://www.conarq.gov.br/resolucoes-do-conarq/266-resolucao-n-24,de-3-de-agosto-de-2006.html>. Acesso em: 14 de jan. 2016.

CONSELHO NACIONAL DE ARQUIVOS (CONARQ). Resolução no 25, de 27 de abril de 2007. Dispõe sobre a adoção do Modelo de Requisitos para Sistemas Informatizados de Gestão Arquivística de Documentos - e-ARQ Brasil. Disponível em: <http://conarq.arquivonacional.gov.br/resolucoesdo-conarq/267-resolucao-n-25,-de-27-de-abril-de-2007.html>. Acesso em 14 jan. 2016.

CONSELHO NACIONAL DE ARQUIVOS (CONARQ). Resolução no 31, de 28 de abril de 2010. Dispõe sobre a adoção das Recomendações para Digitalização de Documentos Arquivísticos Permanentes. Disponível em: <http://conarq.arquivonacional.gov.br/images/publicacoes_textos/Recom endacoes_digitalizacao_completa.pdf>. Acesso em: 14 jan. 2016.

CONSELHO NACIONAL DE ARQUIVOS (CONARQ). Resolução no 32, de 17 de maio de 2010. Dispõe sobre a inserção dos Metadados na Parte II do Modelo de Requisitos para Sistemas Informatizados de Gestão Arquivística de Documentos - e-ARQ Brasil. Disponível em: <http://conarq.arquivonacional.gov.br/resolucoes-do-conarq/274resolucao-n-32,-de-17-de-maio-de-2010.html>. Acesso em: 14 jan. 2016. CONSELHO NACIONAL DE ARQUIVOS (CONARQ). Resolução no 37, de 19 de dezembro de 2012. Aprova as Diretrizes para a Presunção de Autenticidade de Documentos Arquivísticos Digitais. Disponível em: < http://www.conarq.gov.br/resolucoes-do-conarq/279-resolucao-n-37,-de19-de-dezembro-de-2012.html>. Acesso em: 14 jan. 2016.

CONSELHO NACIONAL DE ARQUIVOS (CONARQ). Resolução no 39, de 29 de abril de 2014. Estabelece diretrizes para a implementação de repositórios arquivísticos digitais confiáveis para o arquivamento e 
manutenção de documentos arquivísticos digitais em suas fases corrente, intermediária e permanente, dos órgãos e entidades integrantes do Sistema Nacional de Arquivos - SINAR. Disponível em: < http://www.conarq.gov.br/resolucoes-do-conarq/281-resolucao-n-39-de29-de-abril-de-2014.html>. Acesso em: 14 jan. 2016.

FERREIRA, M. Introdução à preservação digital: conceitos, estratégias e atuais consensos. Guimarães, Portugal: Escola de Engenharia da Universidade do Minho, 2006.

FLORES, D.; BAGGIO, C. C. Documentos digitais: preservação e estratégias. Biblos: Revista do Instituto de Ciências Humanas e da Informação, v. 27, n. 1, p. 11-24, jan./jun. 2013.

\section{INSTITUTO BRASILEIRO DE INFORMAÇÃO EM CIÊNCIA E TECNOLOGIA (IBCT).}

Rede Brasileira de Serviços de Preservação Digital - Cariniana. Sobre a Rede. 2016.

Disponível em: < http://www.ibict.br/pesquisa-desenvolvimentotecnologico-einovacao/

rede-brasileira-de-servicos-de-preservacao-digital>. Acesso em: 22 de jul. 2016.

INNARELLI, H. C. Gestão de preservação de documentos arquivísticos digitais: proposta de um modelo conceitual. 2015. 348f. Tese (Doutorado em Ciências da Informação) - Escola de Comunicações e Artes, Universidade de São Paulo, São Paulo.

INTERNATIONAL ORGANIZATION FOR STANDARDIZATION (ISO). ISO TC 46/SC/11. About. Disponível em: < https://committee.iso.org/home/tc46sc11 >. Acesso em 14 jan. 2016.

JENKINSON, H. A manual of archive administration. London: Percy Lund, Humphries, 1922.

MINISTÉRIO DA INTEGRAÇÃO NACIONAL (BRASIL). Portaria no 29, de 10 de março de 2015. Dispõe sobre o fornecimento, pelos bancos administradores dos Fundos Constitucionais de Financiamento, das informações necessárias à supervisão, ao acompanhamento e ao controle da aplicação dos recursos e à avaliação de desempenho desses Fundos, com base no art. 70 da Lei no 10.177, de 12 de janeiro de 2001. Disponível em: <http://www.mi.gov.br/documents/10157/1467590/PORTARIA+MI+29+2 015.pdf/0579fab8-52b1-443c-8d5f-30f315301464>. Acesso em 3 set. 2018.

MINISTÉRIO DA PREVIDÊNCIA SOCIAL (BRASIL). Portaria no 157, de 3 de abril de 2013. Aprova o Módulo II do Manual de Gestão da Informação e Documentação - MGID no âmbito do Ministério da Previdência Social e de suas entidades vinculadas.

Disponível em: 
http://www.editoramagister.com/legis 24297227 PORTARIA N 157 DE 2 DE ABRIL DE 2013.aspx>. Acesso em: 14 jan. 2016.

MINISTÉRIO DA PREVIDÊNCIA SOCIAL (BRASIL). Portaria no 368, de 18 de agosto de 2015. Aprova o Módulo I - Planejar a gestão da informação e documentação do Manual de Gestão da Informação e Documentação MGID, no âmbito do Ministério da Previdência Social e de suas entidades

Disponível em:

http://www.codigoslex.com.br/legis 27015270 PORTARIA N 368 DE 18 DE AGOSTO DE 2015.aspx>. Acesso em: 14 jan. 2016.

SANTOS, V. B. Preservação de documentos arquivísticos digitais. Ci. Inf., Brasília, DF, v. 41, n. 1, p. 114-126, jan./abr., 2012.

SILVA, E. L. da. Metodologia da pesquisa e elaboração de dissertação. 4. ed. rev. atual. - Florianópolis: UFSC, 2005.

THE INTERNATIONAL RESEARCH ON PERMANENT AUTHENTIC RECORDS IN ELECTRONIC SYSTEMS (InterPARES 2 Project). Diretrizes do preservador: a preservação de documentos arquivísticos digitais; diretrizes para organizações. TEAM Brasil. Tradução: Arquivo Nacional e Câmara dos Deputados. 2007. Disponível em: <http://Conarq.interpares.org/display_file.cfm?doc=ip2_preserver_guideli nes_booklet--portuguese.pdf>. Acesso em 20 jun. 2015. 